\title{
Heat transfer Augmentation of Gravity Assisted Multi Heat pipe Induced Heat Exchanger
}

\author{
P. Ram Kumar, M. Sivasu bramanian, P.RajeshKanna, P.Raveendiran
}

\begin{abstract}
Heat transfer augmentation of a heat exchanger with a multi-heat pipe has been investigated with the influence of gravity assistance. The working fluids used to analyse the performance are methanol and acetone. Water is used as a heat transfer fluid. In which, the analysis is carried out with the gravity-assisted angles of $0^{\circ}, 45^{\circ}$ and $90^{\circ}$. In this work, various parameters such as temperatures of hot water ranges $50^{\circ} \mathrm{C}, 60^{\circ} \mathrm{C}$, $70^{\circ} \mathrm{C}$, and cold water temperature are observed as $32.5^{\circ} \mathrm{C}$ throughout the investigation. Hot water mass flow rates as 40 $\mathrm{LPH}$ to $120 \mathrm{LPH}$ with an increase of $20 \mathrm{LPH}$, cold water as 20 $\mathrm{LPH}$ to $60 \mathrm{LPH}$ with an increase of $10 \mathrm{LPH}$. The result reveals that increase in effectiveness occurs at an angle of $0^{\circ}$ for Acetone with $60^{\circ} \mathrm{C}$ and $100 \mathrm{LPH}$ is $71.5 \%$ of an increase in effectiveness is achieved than methanol for optimum said conditions.
\end{abstract}

Keywords : Heat pipe, heat exchanger, Gravity-assisted angles, Mass flow rate, Effectiveness.

\section{INTRODUCTION}

$\mathrm{I}_{\mathrm{n}}$ many processing plant, heat recovery systems, space applications heat transfer performance in widely achieved using heat pipe. The gravitational influence shows improvement in performance was analysed by segments of the heat pipe [1 -2]. The heat pipe used for various applications was analysed with numerical and experimental studies were stated in [3-4]. Esarte and Domiguez [5] experimented the flat heat pipes working against gravitational influence. In which thermal resistance was less and the coefficient of performance have twice the value than theoretical prediction. Luis Diego Fonseca et al. [6] analysis reveals with varying the working fluid with different fill ratios within $20 \%$ to $90 \%$, the optimal thermal performance at a fluid ratio was $69.68 \%$.

Shabgard et al. [7] applied a model on a thermal network to characterize the thermal behaviour in a high-temperature latent heat thermal energy storage system. Hossain et al. [8] observed result shows that performance depends upon different tilt angles and various heat input does not depend on

Revised Manuscript Received on December 5, 2019

* Correspondence Author

P. RamKumar *, Department of Mechanical Engineering, Kalasalingam Academy of Research and Education, Krishnankoil, Virudhunagar, 626126, Tamil Nadu, India. Email: rkmailmech@gmail.com

M.Sivasubramanian, Department of Automobile Engineering, Kalasalingam Academy of Research and Education, Krishnankoil, Virudhunagar, 626126, Tamil Nadu, India. Email: m.sivasubramanian@klu.ac.in

P.RajeshKanna, Department of Mechanical Engineering, Al Ghurair University, Dubai, United Arab Emirates. Email: prkanna@gmail.com

P.Raveendiran, Department of Mechanical Engineering, Alagappa Chettiar Government College of Engineering and Technology, Alagappa University, Karaikudi - 630003, Tamil Nadu, India. Email: praveendiran@gmail.com the coolant flow rate. The study shows that for the similar input of heat and tilt angle with acetone for a micro heat pipe shows improved performance.

Influence of nanofluids as working fluid for heat pipe was studied with several tested were stated in [9 -10]. The heat pipe with different materials and tilt angles were analysed with the wick of the heat pipe were reported [11-12]. Heat pipe with various working fluids and filling ratios were investigated for various applications revealed in [13-14]. Iş1k et al [15] fabricated a heat pipe using ammonia. The investigation was made on space applications and burst test in the heat pipe.

In the research by vast investigators, their research was done with minimum geometrical constraints on heat pipe heat exchanger. The constraints includes were geometrical parameters, working fluids, fill ratios and heat transfer fluids in heat pipe. To rectify the above-stated constraints in this investigation, the multi-heat pipes are designed and analysed with a shell assisted heat exchanger under the influence of gravitational effect. In further analysis is carried out with different tilt angles and working fluids. The inlet parameters of the heat transfer fluids are measured with various mass flow rates and temperature inputs.

\section{FABRICATION AND WORKING PROCESS}

\section{A. Fabrication of setup}

To study the heat transfer characteristics of a GAMHPIHE, an experimental setup is designed and given in Figure 1. In this work, GAMHPIHE is fabricated with three heat pipe in which copper as a heat pipe material and Galvanized Iron as shell material for heat exchanger with a diameter of $102 \mathrm{~mm}$ and length of $700 \mathrm{~mm}$ at evaporator zone. Heat pipe inner and outer diameter as 19 and $17 \mathrm{~mm}$ and total length as $1000 \mathrm{~mm}$. Condenser diameter as $35 \mathrm{~mm}$ and length of $200 \mathrm{~mm}$ and adiabatic length of $100 \mathrm{~mm}$.

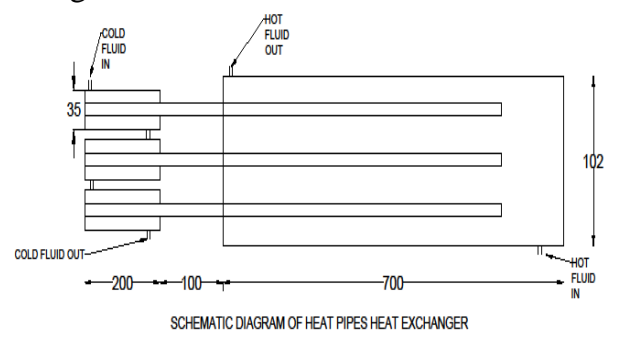

Figure 1. Schematic diagram of a Multi Heat-pipe Heat exchanger

The two water tanks, for hot and cold water with a capacity of five liters. 


\section{Heat transfer Augmentation of Gravity Assisted Multi Heat pipe Induced Heat Exchanger}

Which contains one coiled immersion electric heater with two Kilowatts and a temperature controller to regulate the temperatures of hot water. The rotameters with a range of three Liter per minute are used to regulate the flow rates of both hot and cold water. Two thermocouples observe the external surface temperatures of the evaporator and condenser regions to measure the temperature interface with the environment.

Table 1. Thermo-physical properties of working fluids

\begin{tabular}{|l|c|c|}
\hline Properties & Methanol & Acetone \\
\hline Boiling point & $64^{\circ} \mathrm{C}$ & $56.08^{\circ} \mathrm{C}$ \\
\hline Melting point & $-97.9^{\circ} \mathrm{C}$ & $-94.9^{\circ} \mathrm{C}$ \\
\hline $\begin{array}{l}\text { Latent heat of } \\
\text { evaporation }(\lambda)\end{array}$ & $1055 \mathrm{~kJ} / \mathrm{kg}$ & $534 \mathrm{~kJ} / \mathrm{kg}$ \\
\hline Density of liquid $\left(\rho_{l}\right)$ & $746.2 \mathrm{~kg} / \mathrm{m}^{3}$ & $784.5 \mathrm{~kg} / \mathrm{m}^{3}$ \\
\hline
\end{tabular}

\section{B. Working Process}

At the primary test, heat pipes are filled with methanol and the second test is made with acetone as working fluids. Methanol and Acetone are charged with fill ratios of one hundred percent, the thermophysical properties of working fluids are shown in Table 1. The heat transfer fluid is chosen as water for the analysis.

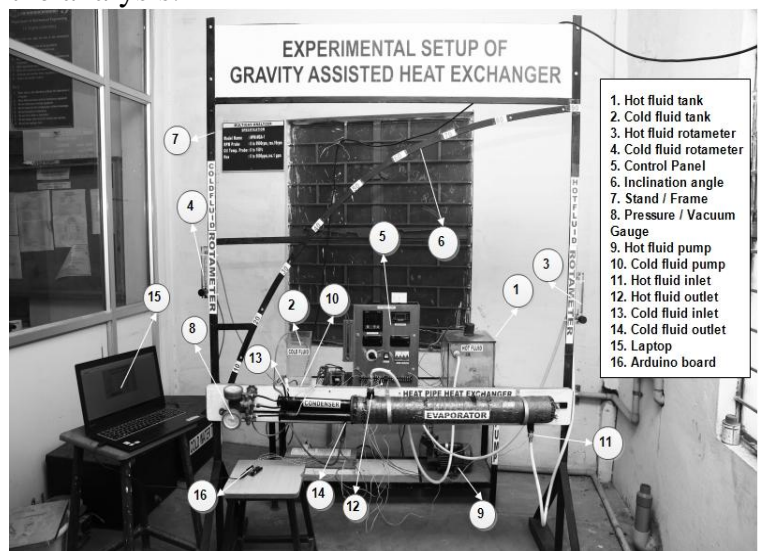

Fig 2 Experimental setup of the Multi-Heat pipe heat exchanger

At the primary stage, GAMHPIHE is kept at a $0^{\circ}$ tilt angle (horizontal axis) and the WF as methanol and water as HTF as shown in figure 2. The Hot water mass flow rate and inlet temperature are fixed as $40 \mathrm{LPH}$ and $50{ }^{\circ} \mathrm{C}$. The mass flow rate of cold water and inlet temperature as $20 \mathrm{LPH}$ and 32.5 ${ }^{\circ} \mathrm{C}$ as the ambient temperature condition for the analysis. At the evaporator zone of a heat exchanger, hot water exchanges the heat to the methanol in the heat pipe. Thus WF absorbs the heat and latent heat of phase change have occurred. The investigation is further carried out with other tilt angles of $45^{\circ}$ and $90^{\circ}$. The hot and cold zones mass flow rates are given in LPH such as 60, 80, 100, 120 and 30, 40, 50, 60. Temperatures at an inlet of hot and cold zones are $60{ }^{\circ} \mathrm{C}, 70$ ${ }^{\circ} \mathrm{C}$, and $32.5{ }^{\circ} \mathrm{C}$. The above conditions are repeated for Acetone as WF and investigation is carried out for similar conditions.

\section{RESULTS AND DISCUSSION}

To investigate the fabricated GAMHPIHE, the analysis is carried out by the above-stated parameters, Figure 3 predicts the mass flow rate of hot water on effectiveness. This graph predicts that by using water as HTF and methanol as WF for the first test. The inlet temperature of hot water as $60^{\circ} \mathrm{C}$ and for varying $\mathrm{m}_{\mathrm{hi}}$ from $40 \mathrm{LPH}$ to $120 \mathrm{LPH}$ and $\psi$ as $0^{\circ}, 45^{\circ}$ and $90^{\circ}$. The maximum effectiveness observed is $34.5 \%$ at $100 \mathrm{LPH}$ and $\psi$ as $0^{\circ}$ than other tilt angles and mass flow rates of hot water. When the mass flow rate increases by $120 \mathrm{LPH}$ the achieved effectiveness is $25.8 \%$ for $0^{\circ}$. In the second test, WF is chosen as Acetone and HTF as water. The above-stated conditions are fixed, at $100 \mathrm{LPH}$ the observed effectiveness is $59.27 \%$ for $0^{\circ}$. At $120 \mathrm{LPH}$ the achieved effectiveness is $45.45 \%$ for $0^{\circ}$. In this investigation also similar trends of graphs are predicted for $100 \mathrm{LPH}$ and 120 LPH. While comparing the tilt angles also $0^{\circ}$ and $90^{\circ}$ show similar ranges of effectiveness than $45^{\circ}$. In both working fluids, the $45^{\circ}$ shows inferior values than other tilt angles, this is due to the effect of gravitational there is a formation of a liquid film at vapour core region, which reduces the phase transformation of working fluids at evaporator region inside the heat pipe, this reduces the heat absorption capacity. Similarly while improving the $\mathrm{m}_{\mathrm{hi}}$ from $100 \mathrm{LPH}$ to $120 \mathrm{LPH}$ the same decrement in effectiveness is achieved for both working fluids. This decrement in effectiveness is due to the minimum heat absorption and release capability of the hot and cold fluid at both zones of the heat pipe. This graph reveals that acetone has maximum effectiveness than methanol at a tilt angle of $0^{\circ}, \mathrm{T}_{\mathrm{hi}}$ as $60^{\circ} \mathrm{C}$ and $\mathrm{m}_{\mathrm{hi}}$ as $100 \mathrm{LPH}$. Therefore, the effectiveness is calculated by equation (1)

$$
\in=\frac{T_{c_{o}}-T_{c_{i}}}{T_{h_{i}}-T_{c_{i}}}
$$

Figure 4 depicts the inclination angle on effectiveness to the temperature of the hot fluid inlet with water as HTF and methanol as WF, the observed maximum mass flow rate of hot water is $100 \mathrm{LPH}$ for various inclination angles $(\psi)$ as $0^{\circ}, 45^{\circ}$ and $90^{\circ}$. The observation stated that the increment of effectiveness is attained from $30.85 \%$ to $34.54 \%$ for $\psi$ as $0^{\circ}$ for $\mathrm{T}_{\mathrm{hi}}$ of $50^{\circ} \mathrm{C}$ to $60^{\circ} \mathrm{C}$. Similarly, for $\mathrm{T}_{\mathrm{hi}}$ as $60^{\circ} \mathrm{C}$ to $70^{\circ} \mathrm{C}$ the effectiveness starts reducing from $34.54 \%$ to $19.73 \%$ for $\psi$ as $0^{\circ}$. In the above observation, it reveals that at $100 \mathrm{LPH}$ at a tilt angle of $0^{\circ}$ maximum effectiveness have been achieved while comparing with other tilt angles. While comparing the temperatures of hot water mass flow rate at $60^{\circ} \mathrm{C}$ shows increment in effectiveness than $50^{\circ} \mathrm{C}$ and $70^{\circ} \mathrm{C}$. Similarly for Acetone also same trends of graphs are observed at $\psi$ as $0^{\circ}$ for $\mathrm{T}_{\text {hi }}$ as $60^{\circ} \mathrm{C}$ the observed effectiveness is $59.27 \%$. At inclination angle of $45^{\circ}$ and $90^{\circ}$ for temperature increment, there is increasing in effectiveness is observed but while comparing with $0^{\circ}$ effectiveness of the system gets reduced. This graph also clearly reveals that at $0^{\circ}, 60^{\circ} \mathrm{C}$ and $100 \mathrm{LPH}$ the acetone shows superior results than methanol. 


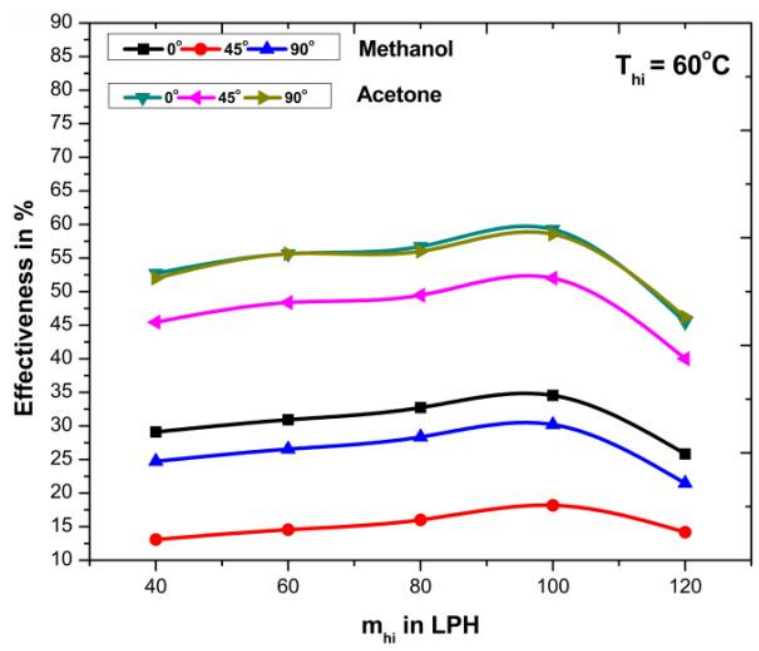

Fig 3 Mass flow rate of hot fluid on Effectiveness

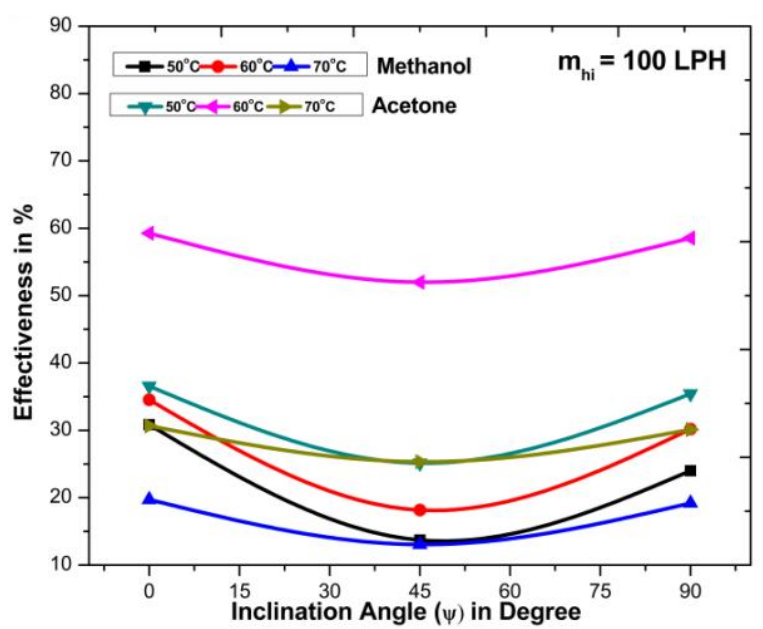

Fig 4 Inclination angle on Effectiveness

Figure 5 inferred the mass flow rate on the heat transfer rate. The conditions for the observation are $\mathrm{T}_{\mathrm{hi}}$ as $60^{\circ} \mathrm{C}, \mathrm{m}_{\mathrm{hi}}$ ranges from $40 \mathrm{LPH}$ to $120 \mathrm{LPH}$ and varying the inclination angles from $0^{\circ}, 45^{\circ}$ and $90^{\circ}$. In the first test, methanol is used as WF. The heat transfer rate (Q) shows increment for $40 \mathrm{LPH}$ to $100 \mathrm{LPH}$ at the range of $186 \mathrm{~W}$ to $552 \mathrm{~W}$ for $\psi$ as $0^{\circ}$. Similarly, for $120 \mathrm{LPH}$, the Q value is $495 \mathrm{~W}$ for $\psi$ as $0^{\circ}$. This plot reveals that $100 \mathrm{LPH}$ shows the highest heat transfer rate in the system. In the second test with acetone as WF. The similar type of trends is achieved. The heat transfer rate (Q) shows increment for $40 \mathrm{LPH}$ to $100 \mathrm{LPH}$ at the range of $337 \mathrm{~W}$ to $948 \mathrm{~W}$ for $\psi$ as $0^{\circ}$. Similarly, for 120 $\mathrm{LPH}$, the $\mathrm{Q}$ value is $872 \mathrm{~W}$ for $\psi$ as $0^{\circ}$. This observation also reveals the same results at $100 \mathrm{LPH}$ maximum $(\mathrm{Q})$ values are achieved than $120 \mathrm{LPH}$. In both the investigations at $100 \mathrm{LPH}$ and $\psi$ as $0^{\circ}$ has highest results, but by comparing both the working fluids acetone shows superior heat transfer rate than methanol. This increase in heat transfer rate is achieved by the maximum absorption of heat energy by the cold fluid at the condenser zone. When the hot fluid inlet temperature at $60^{\circ} \mathrm{C}$ there is maximum heat transfer happens between HTF and working fluids at the evaporator zone. This decrease in trends shows lack of heat transfer at the $45^{\circ}$ with a minimum release of sensible heat and effect of friction occurs due to gravitational effect at condenser region of the heat pipe. Hence, the heat transfer rate is calculated using the below formula (2) and (3)

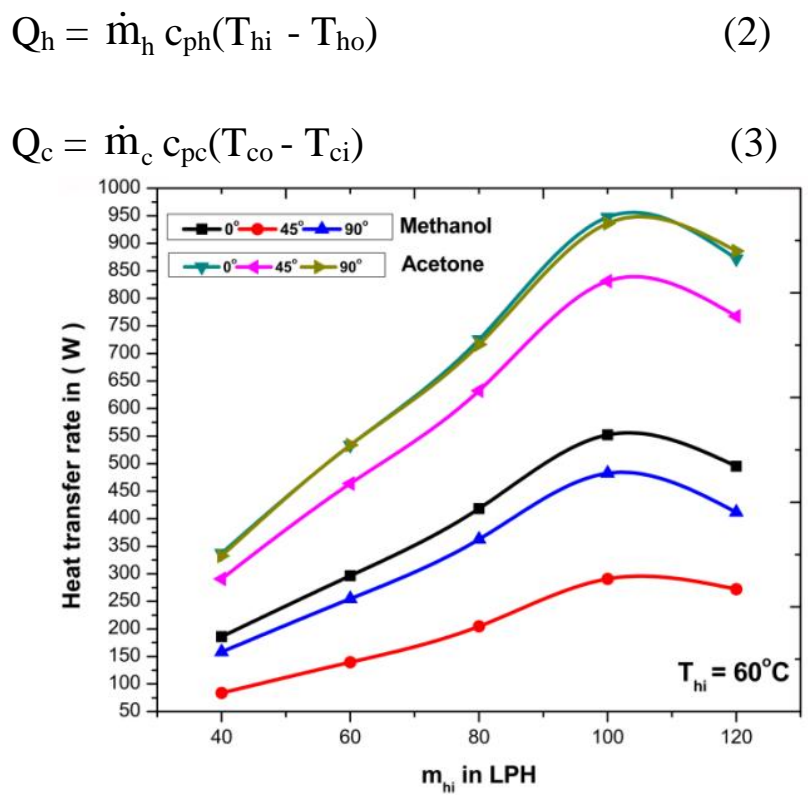

Fig 5 Mass flow rate on Heat transfer rate

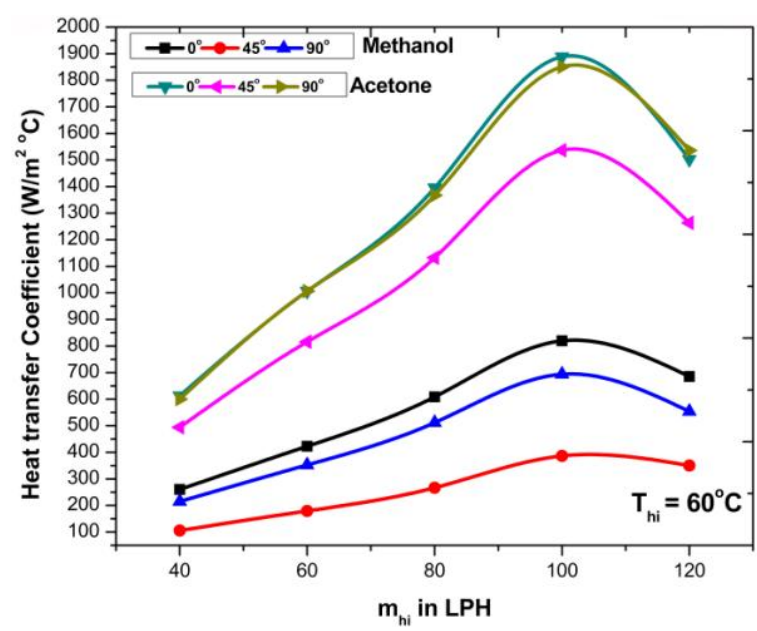

Fig 6 Mass flow rate on heat transfer coefficient

Figure 6 shows that mass flow rate on the heat transfer coefficient with water as HTF. The conditions for observation are $\mathrm{T}_{\mathrm{hi}}$ as $60^{\circ} \mathrm{C}, \mathrm{m}_{\mathrm{hi}}$ from $40 \mathrm{LPH}$ to $120 \mathrm{LPH}$ and varying inclination angle from $0^{\circ}, 45^{\circ}$ and $90^{\circ}$. The observed heat transfer coefficient (h) at $40 \mathrm{LPH}$ to $100 \mathrm{LPH}$ for $\psi$ as $0^{\circ}$ is $260.37 \mathrm{~W} / \mathrm{m}^{2}{ }^{\circ} \mathrm{C}$ to $819.41 \mathrm{~W} / \mathrm{m}^{2}{ }^{\circ} \mathrm{C}$. At $120 \mathrm{LPH}, \psi$ as $0^{\circ}$ the observed value is $685.60 \mathrm{~W} / \mathrm{m}^{2}{ }^{\circ} \mathrm{C}$. In Acetone as WF the similar value of trends is observed. At $40 \mathrm{LPH}$ to $100 \mathrm{LPH}$ the observed (h) value ranges as $613.11 \mathrm{~W} / \mathrm{m}^{2}{ }^{\circ} \mathrm{C}$ to 1888.67 $\mathrm{W} / \mathrm{m}^{2}{ }^{\circ} \mathrm{C}$ for $\psi$ as $0^{\circ}$. Similarly for $120 \mathrm{LPH}$ the observed (h) as $1508.28 \mathrm{~W} / \mathrm{m}^{2}{ }^{\circ} \mathrm{C}$ for $\psi$ as $0^{\circ}$. This both working fluid shows similar trends in the investigation at $100 \mathrm{LPH}$ highest value of $(\mathrm{h})$ is achieved than $120 \mathrm{LPH}$. While considering the tilt angles the horizontal axis $\psi$ as $0^{\circ}$ possess maximum heat transfer coefficient than $\psi$ as $45^{\circ}$ and $90^{\circ}$. Using the below equation the convective heat transfer coefficient of cold fluid on GAMHPIHE is analysed by the equation (4)

$\mathrm{h}=\frac{Q c}{A^{*}(\Delta T)_{l m}}$ 


\section{Heat transfer Augmentation of Gravity Assisted Multi Heat pipe Induced Heat Exchanger}

In comparing the $0^{\circ}$ and $90^{\circ}$ the similar range of values are achieved than at $45^{\circ}$. This predicts the higher heat transfer coefficient at hot fluid for $100 \mathrm{LPH}$ and $60^{\circ} \mathrm{C}$ with the $0^{\circ}$ inclination angle for acetone as WF. This is due to the higher release of sensible heat to the cold fluid, by the working fluids which lead to maximum heat transfer along with the system.

\section{CONCLUSION}

- It is inferred that optimum conditions observed from the investigation are hot fluid mass flow rates $\left(\mathrm{m}_{\mathrm{hi}}\right)$ as 100 $\mathrm{LPH}$ and cold fluid $\left(\mathrm{m}_{\mathrm{ci}}\right)$ as $50 \mathrm{LPH}$, hot fluid at an inlet temperature $\left(\mathrm{T}_{\mathrm{hi}}\right)$ as $60^{\circ} \mathrm{C}$, the inclination angle $(\psi)$ as $0^{\circ}$ (Horizontal axis).

- While comparing both working fluids for above-revealed conditions, acetone shows maximum results when comparing with methanol. There is an increment in results of $71.57 \%$ for effectiveness, $72 \%$ for heat transfer rate, $130.49 \%$ for heat transfer coefficient are achieved.

- This investigation reveals that Multi heat pipe induced in the heat exchanger with acetone shows superior in results while comparing with methanol in all the observed conditions of the investigation.

\section{APPENDIX}

\author{
Nomenclature \\ A - Area of heat transfer $\left(\mathrm{m}^{2}\right)$ \\ $\mathrm{C}$ - Heat capacity rate $(\mathrm{kW} / \mathrm{K})$ \\ $\mathrm{C}_{\mathrm{p}}$ - Specific heat of the fluid $(\mathrm{kJ} / \mathrm{kg} \mathrm{K})$ \\ D - Diameter (m) \\ $\mathrm{h}$ - Heat transfer coefficient $\left(\mathrm{W} / \mathrm{m}^{2 \mathrm{o}} \mathrm{C}\right)$ \\ L - Length (mm) \\ $\mathrm{m}$ - Mass flow rate of fluid (LPH) \\ $\mathrm{Q}$ - Heat transfer rate (W)
}

Abbreviations

GAMHPIHE - Gravity Assisted Multi Heat Pipe Induced Heat exchanger

$\begin{array}{ll}\text { HTF } & - \text { Heat Transfer Fluid } \\ \text { LPM } & - \text { Liter Per Minute } \\ \text { WF } & - \text { Working Fluid }\end{array}$

\section{Greek Letters}

$(\Delta \mathrm{T})_{\mathrm{lm}}-$ Log mean temperature difference, $\left({ }^{\circ} \mathrm{C}\right)$

$\in \quad-$ Effectiveness, $(\%)$

$\psi \quad$ - Tilt angle / Inclination angle, $\left({ }^{\circ}\right)$

\section{REFERENCES}

[1] Alicetin Gurses, Cannistrano. C, "The inclination effect on the performance of water-filled heat pipes," Renewable Energy, 1991, 1, pp. 667-674

[2] Khalid Joudi. A, Witwit. A. M, "Improvements of gravity assisted wickless heat pipes," Energy Conversion and Management, 2000, 41, pp. 2041-2061

[3] Didi Zhang, Gang Li, Yuging Liu, Xialiang Tian, "Simulation and experimental studies of R134a flow condensation in a pump assisted separate heat pipe," International Journal of heat and mass transfer, 2018, 126, pp. 1020-1030

[4] Lydia Wermer. R, Martin Ward. J, Justin Simpson. D, Robert Zimmerman. A, James Stewart. A, "A high capacity self priming counter gravity heat pipe," International Journal of Heat and Mass Transfer, 2018, 125, pp. 1369-1378

[5] Esarte. J, Domiguez. M, "Experimental analysis of a flat heat-pipe working against gravity," Applied Thermal Engineering, 2003, 23, pp. 1619-1627

[6] Luis Diego Fonseca, John, Franklin Miller, "Result of a three evaporator in cryogenic helium heat pipe," International Journal of Heat and Mass Transfer, 2018, 120, pp. 1275-1286
[7] Shabgard. H, Bergman. T.L, Shariti. N, Faghri. A, "High temperature latent heat thermal energy storage using heat pipes," International Journal of Heat and Mass Transfer, 2010, 53, pp. 2979-2988

[8] Hossain. R.A, M.A.K. Chowdhuri, Feroz. C.M, "Design fabrication and experimental study of heat transfer characteristics of a Micro Heat Pipe," Jordan Journal of Mechanical and Industrial Engineering, 2010, 4, pp. 531-542

[9] Kempers. R, Ewing. D, Ching. C. Y, "Effect of number of mesh layers and fluid loading on the performance of screen mesh wicked heat pipes," Applied Thermal Engineering, 2006, 26, pp. 89-595

[10] Shafai. M, Blanoco. V, Vafai. K, and Manco. O, "An investigation of the thermal performance of cylindrical heat pipes using nanofluid," International Journal of Heat and Mass Transfer, 2010, 53, pp. 376-383

[11]Said Salem. A, Bilal Akash. A, "Experimental performance of a heat pipe," International Communication of Heat and Mass Transfer, 1999, 26 (5), pp. 679-684

[12]Pis mennyi. E.N, Khayrnasov. S.M, Rassamakin. B.M, "Heat transfer in evaporation zone of aluminium grooved heat pipes," International journal of Heat and Mass Transfer, 2018, 127, pp. 80-88

[13]Durga Bastakoti, Hongna Zhang, WeihuaCai, Fengchen Li, "An experimental investigation of thermal performance of pulsating heat pipe with alcohols and surfactant solutions," International Journal of Heat and Mass Transfer, 2018, 117, pp. 1032-1040

[14] Vivek Patel. K, "An efficient optimization and comparative analysis of ammonia and methanol heat pipe for satellite application," Energy conversion and Management, 2018, 165, pp. 382-395

[15]Işı1k. H.G, Ömür. C, Uygur. A.B, Horuz. I, “A novel burst test approach for the qualification of heat pipes developed for space applications," International Journal of Pressure Vessels and Piping, 2018, 165, pp. 241-248

\section{AUTHORS PROFILE}

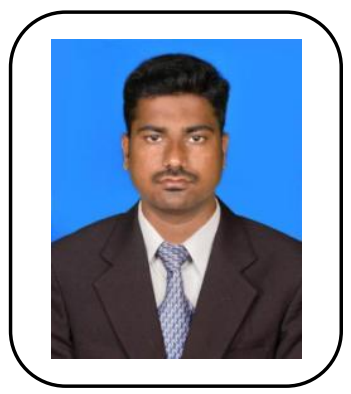

Mr. P.Ramkumar, Assistant Professor in Mechanical Engineering at Kalasalingam University. I have completed B.E (Mechanical Engineering), M.E (Thermal Power Engineering), pursuing Ph.D. (Thermal Engineering) having five years of teaching experience for U.G and P.G students. I am life time member of Indian Society of Heat and Mass Transfer (ISHMT - IIT Madras). I have published two papers in International journal, three papers published in International conference and four papers in National conference. I am doing my research in the field of heat pipe and compact heat exchanger.

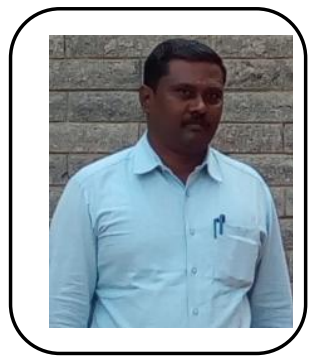

Dr. M. Sivasubramanian, Associate Professor in Automobile Engineering at Kalasalingam University. I have completed $\mathrm{Ph} . \mathrm{D}$ in thermal engineering, I am having twenty years of teaching experience. I am life time member of Indian Society of Heat and Mass Transfer (ISHMT - IIT Madras), MISTE, SAE. Seven papers in International journal and twenty five papers in International / National conference. Research area in the fluid flow.

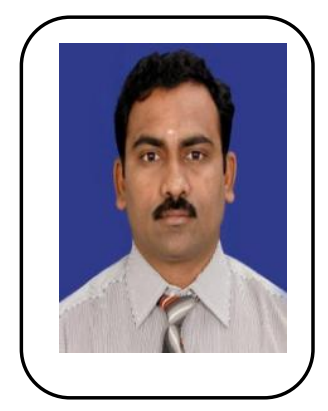

Dr. P. Rajesh Kanna, Professor in Mechanical Engineering at Al Ghurair University, Dubai, United Arab Emirates. I have completed in Ph.D in IIT - Guwahati. Post Doc at National Taiwan University of Science and Technology, Department of Mechanical Engineering, CFD, Taiwan, Taipei. Research expert in experimentation and numerical analysis in heat transfer, fluid mechanics, CFD. His h-index is 16, i-10-index is 21, and Citation Statistics is 611. 


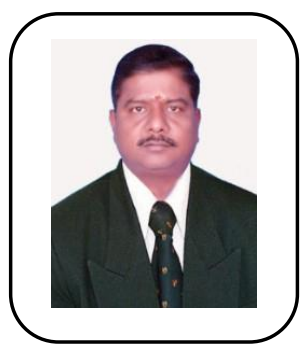

Dr. P. Raveendiran, Associate Professor at Alagappa Chettiar Government College of Engineering and Technology, Alagappa University, Karaikudi. Ph.D has been completed in Annamalai University. I have published Eight International journal, one national journal, and two national / international conferences. One book published in heat and mass transfer. I am having teaching experience of seventeen years. I am expertise in the field of Heat pipe, heat exchanger. 